\title{
Public-private interaction in low-rise, high-density Tokyo: a morphological and functional study of contemporary residential row-houses
}

\author{
Satoshi Sano \\ Keio University, Japan, School of Science for Open and Environmental Systems \\ sanosatoshi@keio.jp
}

Ivan Filipović, Darko Radović

Keio University, Japan, School of Science for Open and

Environmental Systems

ivan.filipovic@keio.jp | radovic@sd.keio.ac.jp

\begin{abstract}
The focus of this paper is liveable, low-rise high-density urban morphologies of residential architecture and urban planning practices in Tokyo. Over the last several decades, historically established qualities in cities worldwide are increasingly sacrificed in favour of globalization-led 'universal' typologies. Tokyo is not an exception: it is gradually changing to a high-rise, high-density built city environment. From a morphological point of view, the paper demonstrates bioclimatic and cultural disadvantages of such developmental paradigm shift in Tokyo. Presented case studies elaborate upon the ways in which low-rise high-density environments and subsequent urban forms better facilitate human interaction and, consequently, can aid in reducing social isolation and contribute to mental well-being.

Presented case studies, observed over the period of six years depict how residential environments created by row-houses can be seen as a collection of adjoining private spaces. The emphasis is on the interconnected set of phenomena: low-rise high-density morphologies, climate-responsive semi-exterior spaces, facilitating human and public-private interaction. The conducted morphological and functional analysis shows how design requirements of bioclimatic responsive semi-exterior space fully coincide with those of desirable public-private interface and human interaction. However, site-specific constraints critically affect spatial configurations of low-rise high-density developments in contemporary Tokyo, emphasizing the requirement for case-by-case attention in design and management of such places. Only design processes conscious of spatial management aware of the potential embedded in the design process can enhance socio-cultural interplay and bioclimatic performance.
\end{abstract}

Keywords: well-being, residential architecture, place management, bioclimatic sustainability, Tokyo

To cite this article:

Sano, S., Filipović, I., Radović, D. (2020). Public-private interaction in low-rise, high-density Tokyo: a morphological and functional study of contemporary residential row-houses. The Journal of Public Space, 5(2), 63-88, DOI 10.3289I/jps.v5i2.1285

This article has been double blind peer reviewed and accepted for publication in The Journal of Public Space. (c) (5) $\$$ This work is licensed under a Creative Commons Attribution - Non Commercial 4.0 International License https://creativecommons.org/licenses/by-nc/4.0/ 


\section{Introduction: Current status and issues of Tokyo. High-rise High-density.}

The focus of this paper is on liveable, low-rise high-density urban fabric of residential Tokyo. Liveability, as a concept, encompasses numerous qualities and predetermined features (see: The Economist's Global Liveability Ranking, Mercer's Quality of Living Rankings, Monocle's Quality of Life Survey etc.), with some publications noting comprehensive assessment methods (Tan et al., 20I2). However, there is still no definitive agreement on particularities necessary to achieve liveability, or about their relevance or methodological assessment (The National Association of Regional Councils, 2012; Veenhoven, 2006). For the purposes of this research, liveability is defined as the possibility for unhindered interaction between various actors in the city, as well as the blurred demarcations between public and private spaces. Additionally, in the context of this research, we use the Japan Property Central KK (20II) definitions of low-rise as any building below four floors (on average ground floor plus two storeys) and high-density is defined by the floor aspect ratio (FAR) over $200 \%$. To illustrate, the highest ratio in Tokyo is $1300 \%$ which applies to commercial land in the Yurakucho/Marunouchi area around Tokyo Station (Japan Property Central KK, 20I I). "Over the last several decades, historically established quality was increasingly sacrificed, in favour of 'universal' typologies, which are, in the name of globalization and single bottom line, destroying cities worldwide" (Radović, 2012. Pp. I07., for further discussion on globalization effects see: Exenberger et al. (20I3), Khazaee et al. (20I5), Kara (2019)). Some areas in Tokyo, such as its central three wards and waterfront areas are gradually losing the low-rise high-density spatial qualities and a particular feel which characterizes this city and its life. As previously noted, spatial density is defined by the Floor Aspect Ratio (FAR) calculated as a building's total floor area (gross floor area) to the size of the piece of land upon which it is built. Simple numbers can illustrate the core problem: the average size of one property in the waterfront area is 7,123 square metres, compared to that of 218 square metres for the rest of Tokyo. The average number of storeys there is ground floor plus 6.3 compared to the ground floor plus 1.6 (Tokyo Metropolitan Government, 2016).

Consequently, Tokyo is gradually changing, and dense, low-rise urban fabric is getting replaced by high-rise high-density developments. A 2019 meta-analysis of 180 studies on a vast number of economic outcomes of urban density concluded that urban density had net positive effects but had some regressive distributional effects, which is to say, a negative impact on lower-income residents (Ahlfeldt and Pietrostefani, 2019).

In Japan's capital city and in a dramatically ageing and depopulating country, high-rise apartment buildings have become a dominant trend. According to the Statistics of Tokyo created by Tokyo Metropolitan Government (2019), between 2008 and 2015, the number of buildings in Tokyo increased by 38,218 for residential buildings, but decreased for all other building types. And the number of buildings of more than 30 storeys has increased by about $50 \%$ in Koto-ward (the ward includes the waterfront area). "Now [...] the urban return phenomenon is intensifying, the housing construction promoted by developers creates the situation there are only high-rise apartment buildings with large open spaces." (Maki et al, 2019, p. 36)

According to the recent report from the Ministry of Health, Labor and Welfare (2008), residents of the high-rise apartment buildings in urban areas, especially elderly people, tend to be drastically confined. This extends to both real and metaphorical terms: an 
average net size of an apartment in Tokyo is approximately 40-65 square meters, usually housing a family of three or more members. In addition, as the households are predominantly multigenerational, larger occupancy is expected. As an ageing society (Statistics Bureau of Japan, 2019), with the world's longest life expectancy (World Health Organization, 2020), older adults have fewer opportunities for interaction within their immediate communities and the city design practices do not facilitate or take into account such activities. This urbo-architectural type allows for less contact with the outside world and subsequently social isolation is more likely (Ministry of Health, Labor and Welfare, 2008). Social isolation is one of the factors that can lead to an increase in the risks of mental illness (Clifford, 2018). If a person suffers from said problems, he/she will likely become reclusive and socially isolated, entering a vicious circle of isolation and illness (Ministry of Health, Labor and Welfare, 2008). According to the research conducted by the Building Research Institute of the Japanese Ministry of Construction, high-rise apartment buildings are 'psychologically problematic' (Watanabe, 1989). An analysis of experiences of the homemakers living in various housing typologies provides conclusive evidence of direct relation with mental well-being (Petermans, 2019, Rice, 2019). The reasons are simple: according to Watanabe (1989), the residents of high-rise apartment buildings are not aware of changes in outside brightness, do not hear the sound of rain, miss on outdoor events or the movement of people, cannot see flowers and trees, in stark contrast to the residents of detached houses. For the residents of high-rise apartments, the amount of external stimuli is exceptionally low, because the ground-level is not only physically but also psychologically distant. All that makes the residents of such neighbourhoods psychologically distant from each other. That study identifies living in high-rise high-density as psychologically isolating.
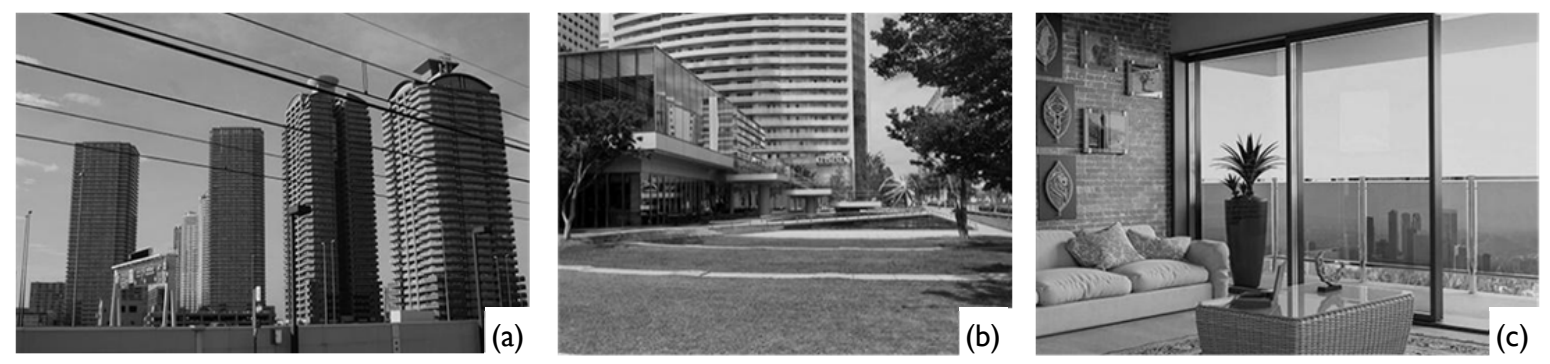

Figure I. Illustrative examples of High-rise High-density Residential Environments: (a) Water front area of

Tokyo (Source: yano@mama.akari.ne.japan'); (b) Large open spaces without social interaction (Source: Thirteen-fri ${ }^{2}$ ); (c) High-rise interior space without external social interaction (Source: edvaldocostacordeiro ${ }^{3}$ )

\footnotetext{
' Available at: https://commons.m.wikimedia.org/wiki/File:Towers_of_Shinonome_\%E6\%9D\%BI\%E9\%9B\%B2\%E3\%82\%BF\%E3\%83\%AF\%E3\%83\%BC\%E3\%83\%9E\%E3\%83\%B3\%E3\%82\%B7 \%E3\%83\%A7\%E3\%83\%B3\%E7\%BE\%A4_-_panoramio.jpg [Accessed 8 Dec. 2019]. Colour-change (to blank and white) by author.

${ }^{2}$ Available at: $h$ ttps://ja.m.wikipedia.org/wiki/\%E3\%83\%95\%E3\%82\%Al\%E3\%82\%A4\%E3\%83\%AB:MM__Grand_Central_Tower_PIR.jpg [Accessed 8 Dec. 2019]. *Trimming and colour-change (to blank and white) by author.

${ }^{3}$ Available at: https://pixabay.com/ja/photos/\%E3\%82\%A6\%E3\%82\%A3\%E3\%83\%B3\%E3\%83\%89\%E3\%82\%A6\%E5\%AE\%B6\%E5\%85\%B7-\%E3\%83\%AB\%E3\%83\%BC\%E3\%83\%A0-3042834/ [Accessed 8 Dec. 2019]. Colour-change (to blank and white) by author.
} 
Urban precincts with multiple residential towers tend to be designed with large open spaces at the ground level. Planning regulations/policies demand that, when the upper limit of the floor area ratio is reached, the building coverage rate must be lowered. If a developer designates the resulting open spaces as 公開空地koukai-kuchi (literally: open vacant space), it becomes legally possible to raise the total floor area (Building Standards Act (Japanese building regulation) No.59-2). Many developers use this legal loophole and, as a direct consequence, a number of open spaces at the foot of residential towers remain vacant (Figure Ib) But, lacking spatial definition and specific use, such spaces are often not used at all, thus failing to perform as places for social interaction.

The motivation of developers to set up 'open vacant spaces' is simple: the goal is to increase the total floor area, not to produce high-quality public spaces for people (Suzuki, 2014). The equation is simple: increased floor area equals increased profit. All efforts go towards reduction of maintenance costs and complaints from future tenants and neighbours, not towards solving the reasons for dissatisfaction. According to Sasao (2019), this problem occurs not in 'open vacant spaces', but likewise in public spaces, such as parks. Various activities which one would expect simply get prohibited (e.g. eating/drinking), on the grounds of avoiding maintenance and management costs. For instance, a common ban gets placed upon children playing or jogging. In extreme cases, even conversation is not allowed. Public spaces were not conceived for people and social interaction and, subsequently, these are spaces without people through which residents only pass by. Without reasons to stay, they will not linger unless necessary. The low level of social interaction in high-rise residential developments is, thus, not limited to the interior; exterior spaces suffer the same fate.

This paper presents an alternative to the high-rise high-density trend, reintroducing the low-rise high-density paradigm which is indigenous to Tokyo and Japanese cities at large. Triggered by the above-described socially triggered challenges of the new trend, lowrise high-density environments introduce combination of spatial, socio-cultural and climatic characteristics of low-rise high-density Tokyo, and efforts towards sustaining and perpetuating said qualities.

Well-being, an important concept for this research, will be brought into an active connection with architectural planning and design, linking it holistically to a number of factors. Well-being presents a state of happiness and contentment, with low levels of distress, overall good physical and mental health and outlook, or good quality of life. In simple terms, well-being can be described as judging life positively and feeling good (Diener et al, 1997, Veenhoven, 2008). Employing previously established concepts, the research presented in this paper will try and answer the question whether it is possible to design architecture that facilitates well-being utilizing a holistic approach that will include, but is not limited to: the users' experience, urban planning and management practices, residential operational practices and bioclimatic architecture. The following case studies will illustrate how it is possible for those facets to converge in an unplanned/spontaneous way, yielding positive effects, but note how no joint effort to institutionalize and/or codify such experiences has been made so far. 


\section{Theoretical Background: Low-rise High-density}

2. I. Low-rise High-density urban typologies in Tokyo

According to Radović (20I2), the urban spaces of Tokyo have historically had low-rise and high-density spatiality. Even though high-rise and high-density urban developments represented by residential towers are taking over, Tokyo still keeps its predominantly low-rise, high-density spatiality.

Tokyo is composed of small land units; the land of Tokyo is shared by 1.8 million landowners. ( 1.7 million individuals and 0.1 million corporate bodies), according to Kitayama et al (2010). The average plot area of a single property in Tokyo is 218 square metres (Tokyo Metropolitan Government, 2016). At morphological level, Tokyo is a dense assemblage of those small units.

The city is predominantly low-rise, with ground floor plus two floor high buildings constituting $70 \%$ of all buildings, with exception of the central three wards of Tokyo, Chiyoda-ward (15\%), Chuo-ward (20\%), Minato-ward (35\%). The average number of storeys of buildings is ground floor plus I.6. (Tokyo Metropolitan Government, 2016) As further elaborated, spaces within low-rise urban fabric, private and public, blend seamlessly, without clear boundaries or an underlying logic.

\subsection{The Street: Where Public and Private Interact}

A number of theorists such as Jinnai, (1995), Sorensen, (2004), Brumann, (2015) tried to explain and define the underlying logic of urban fabric of Tokyo, often in relation to other cities and other cultures. The following references capture some of the dominant discourse.

'Unlike the urban structures one finds in Europe that were created with a series of walls, Tokyo consists of an assemblage of independent buildings (grains). [...] The majority of the land is filled with narrowly segmented, privately-owned living spaces. In these residential areas, spaces that anyone can pass through blend together with private spaces and many of the most private spaces allow a clear of sight from the outside.'

(Kitayama et al, 20I0. pp. 10 and I3I)

That is where

"Ambiguous border between the public and private realms [...] spontaneously emerges, from a kind of collaboration between public and private and nature. [...] Spaces like this are real ad hoc creations. (...) And that is a very interesting, peculiar, practice in Japanese urban space."

(Kuma, 2012, p. 15)

Urban spaces of Tokyo are, thus, recognized as a collection of small spaces in a lowrise, high-density environment, and they have been operated and used privately in response to the Japanese natural environment and its climate in particular. This is where we encounter the expression 'bioclimatic architecture'. The term summarizes a number of differing general terms as the single planning definition - that is a group of design decisions that offer appropriate living conditions within buildings by the minimal use of technical units 'the group of machinery' that require energy consumption of nonrenewable resources (see e.g. Grondin, 1959, Vazquez, 2009, Almusaed, 2014). In bioclimatic terms, the defining extreme is the tropical summer, as the vernacular responses echo those of the cultures to the South of the archipelago - light structure, 
low thermal mass, an emphasis on natural ventilation, openable wall surfaces, elevated floor, in-between “縁側engawa” spaces which accommodate semi-indoor/semi-outdoor living, etc.

Tardits (2014, pp. 213 and 256) argues:

"Like cities in the United States and Africa, Tokyo's public spaces take on different meanings and forms from those in Europe. [...] Agora, forums, plazas, parks, etc. did not appear in Tokyo during the Edo period 5 . Public representation has not developed in Tokyo".

In Japan, the notion of 'public [space]' is a relatively new, imported construct. As Maki et al (2019, pp. 145) pointed out, "The reason why today's Japanese people don't utilize open spaces is that outward urban planning (that does not take into account Japanese cultural background) is forced to apply. [...] Japan's post-war years are not over yet".

Subsequently, what is culture-specific public space for Japan or Tokyo? As mentioned by Kitayama et al (2010), the fabric of Tokyo is finely divided, filled with privately-owned spaces where public and private are mutually interpenetrating. Taking that into account the qualities associated with public-ness and human interaction within small-grained, densely interwoven realms of private and public life can be observed. While plazas and parks were imported to Japan after the Meiji restoration (modernization of Japan after 1868), streets were always spaces for public expression in Japan. Previous research also points out at cultural specificity of Japanese “路地roji”, narrow alleys, where everyday life unfolds. The role of climate-culture nexus in creation of the, 'seamless transition/integration of private and public spaces' (hereinafter: public-private interaction) is confirmed, critical in the definition of the overall Japanese urban condition.

Characteristic to urban spaces of Asia, including Japan, is the presence of “あふうれ出し Afuredashi", privately-owned items (that would normally be stored inside the private property) within the alley space (Tardits, 20I4). Some of Afuredashi examples are pots and plants, household and garden maintenance items such as brooms, rakes, mops, buckets, gardening tools, etc, as well as other various items stored in sheds or storage units, compared to other Western countries. These elements increase utilization of alleyways and stimulate social interaction among residents (e.g. interaction between neighbours while pruning the plants and/or greenery within the boundaries of semipublic spaces or cleaning and general upkeep of said spaces.) (Aoki, Yuasa and Osaragi, 1994).

While it can be argued that the presence of private items in public space exemplifies the dominance of private over public, such interactions (private and public overlapping) increase the opportunities for socialization, at least among residents of the neighbourhood.

Aoki \& Yuasa (1993, pp. 53) pointed out:

\footnotetext{
${ }^{4}$ Engawa: Traditional spatial element of the Japanese architectural space, which is the intermediate area between the interior and the exterior. Engawa has a use as a space to go in and out, to move between rooms, to see outside, to welcome visitors, and so on.

${ }^{5}$ Edo period: The period between 1603 and 1868 in the history of Japan. The period came to an end with the Meiji Restoration (modernization in Japan) starting from 1868.
} 
"In Edo period, the urban blocks of Tokyo were subdivided by roads (alleys) on the premise of private use of public road including even main roads. [...] Operation of road was originally premised on the collaboration of neighbors", while Tardits (2014, pp. 107 and 174) stresses how "The Edo government entrusted the citizen with the day-to-day management of the city, left the city overcrowded [...] In Tokyo, there is no duality of official 'public' and unofficial 'private' [...] Public roads are often violated by private acts and 'tamed'".
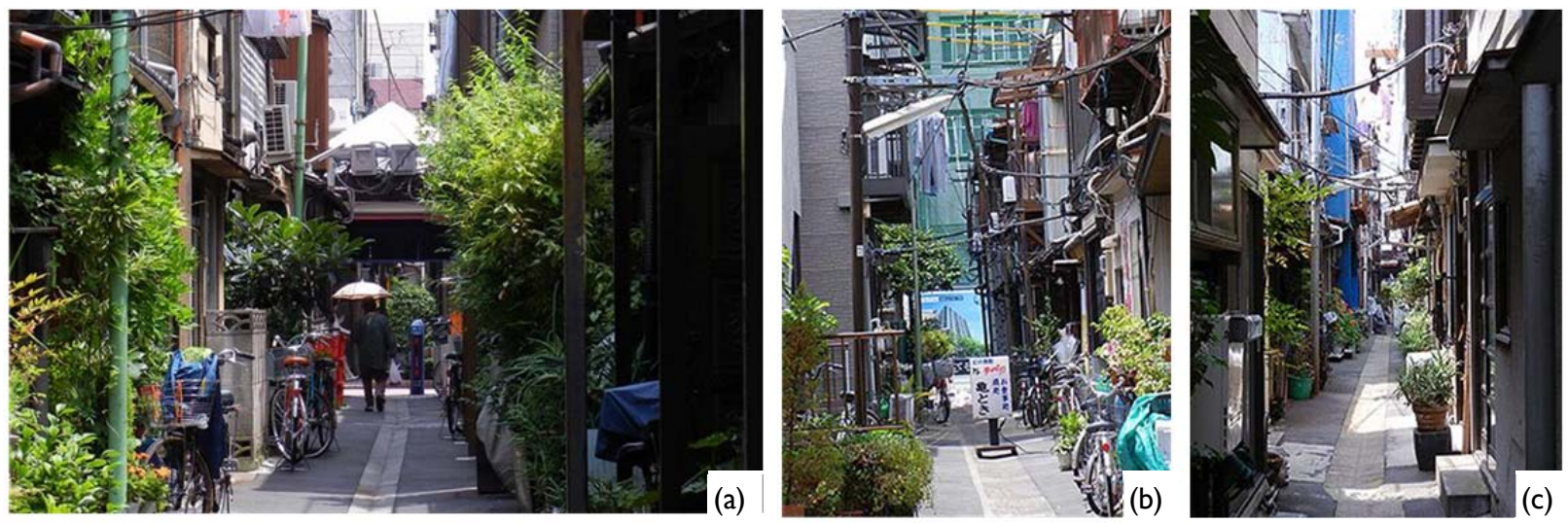

Figure 2. Roji in Tsukishima (Source: Rubber Soul ${ }^{6}$ )

2.3. Semi-Exterior Spatial Nature in Response to Humid Subtropical Climate Japan's humid subtropical climate, predominant in the majority of the country, strongly influences the broadest cultural fabric of Japanese society (Kusanagi, 20I5). The famous saying in Japan 家のつくりやうは、夏をむねとすべし (le no tsukuriyauwa, natsu o mune to subeshi)" means "A house should be built with the summer in mind". This sentence is noted in the essay "Tsurezuregusa" by Yoshida (1330-I33I) and is widely known (Keene, 1998).

Traditionally, Japanese architecture had an open spatial feature that integrates interior and exterior spaces in response to the humid subtropical climate. Kusanagi (2015, pp.37) notes the climate of "Japanese Islands, almost the whole area of about $2000 \mathrm{~km}$ from north to south is humid subtropical climate $(\mathrm{Cfa})^{7 ”}$."

This classification and subsequent architectural practices are in accordance with bioclimatic architecture and concepts of 'passive' design. In the times before 'active', technological climate-control took over, everyday life in semi-exterior space (“軒下空間 Noki-Shita-Kukan") ${ }^{8}$ where direct sunlight is blocked and winds go through created 'public-private interaction'. In contemporary Japan, however, "common areas" (entrance hall, common corridor/steps, elevator hall, an area where different types of functions are mixed), become one of the obstacles.

\footnotetext{
${ }^{6}$ Available at: http://photozou.jp/photo/show//5/764///4/889284 [Accessed 8 Dec. 2019].

${ }^{7}$ World maps of Köppen-Geiger classification. Available at: http://koeppen-geiger.vu-wien.ac.at/ [Accessed 8 Mar. 2020]

${ }^{8}$ Noki-Shita-Kukan: Space under eave and space under roof and massing.
} 

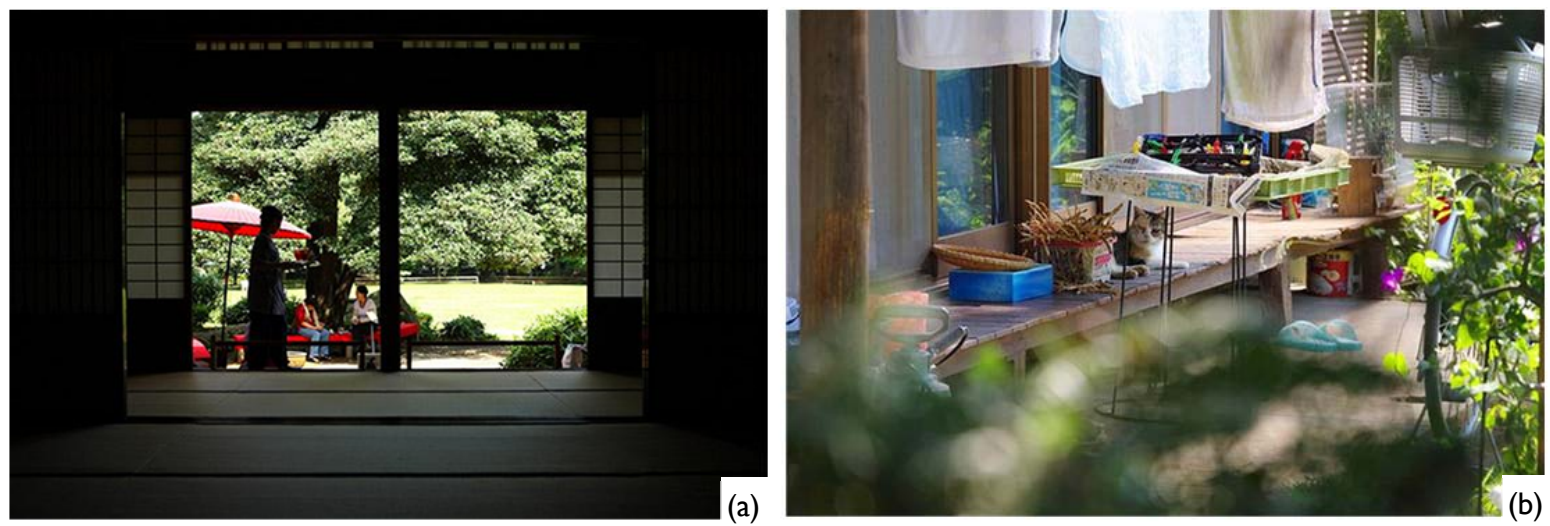

Figure 3. (a) Former Iwasaki House in Taito-ward, Tokyo (Source: mrhayata ${ }^{9}$ );

(b) Anonymous house in Japan (Source: kontenten ${ }^{10}$ )

\subsection{Barrier of Public-Private Interaction}

'Common Areas' can be defined as a space located in-between private spaces, or between private and public spaces. Such spaces have the capacity to enable social interaction, initiated by any party and, thus, acting as a semi-private space.

Unfortunately, this is not its contemporary condition; instead, the private and public spaces are kept apart. The explanations, as is the case with shortcomings associated with high-rise buildings, are to be found in building regulations. The designated common area is assumed to be used by an unspecified number of people. This increases the risk in the case of fire and introduces a set of risk management measures (e.g. evacuation). As a result, the boundary with the private areas must be divided by a fireproof wall. The consequence being that the common-use areas are divided by the firewall located between the private and public spaces, preventing its seamless transition/integration. The second obstacle in reaching the potential of this space is again grounded in regulation - i.e. the question of management: who manages the 'designated common area'? Since this area is not a privately-owned space, the management ought to be handled by a non-tenant. The job of the manager is, again, preventing problems and complaints. Therefore, the number of prohibited actions increases, the same as with open spaces of high-rise developments, making the space difficult for anyone to use. Ironically, the space for everyone becomes the space for no one.

Another issue surrounding the spatial management and residents' interaction can be found in previously noted spatial consequences of imposing the sharing of common areas in a building complex. Imposed spontaneity is seldom successful and continues to be a challenge for architectural designers and spatial managers alike. The fact that the space is clearly marked as a 'designated common [use] area' is synonymous with 'you must share' and 'you must interact with other people here'. The author's experience as an architect shows that people will refuse to use spaces thusly designated and managed (expanded upon in Section 3).

Firstly, the users need a space that can be appropriated as their own, to be utilized as they see fit. Then, the desire of expanding one's space may emerge, which leads to another form of space-sharing. In order to share, it is necessary to communicate with

\footnotetext{
${ }^{9}$ Available at: https://www.flickr.com/photos/mrhayata/382668/ I 24 [Accessed 8 Dec. 2019]

${ }^{10}$ Available at: http://photozou.jp/photo/show/I / 90304/240798820 [Accessed 8 Dec. 2019]
} 
other people and any communication is interaction. Socialization then occurs naturally. In this paper, the focus is on private space/personal space and the possibility to overcome the problems embedded in current 'designated common/public space for nobody' reality. The focus will move to existing apartment buildings, residential environment with private spaces without common areas, and towards the establishment of spatial condition that possibly stimulates the emergence of 'public-private interaction'.

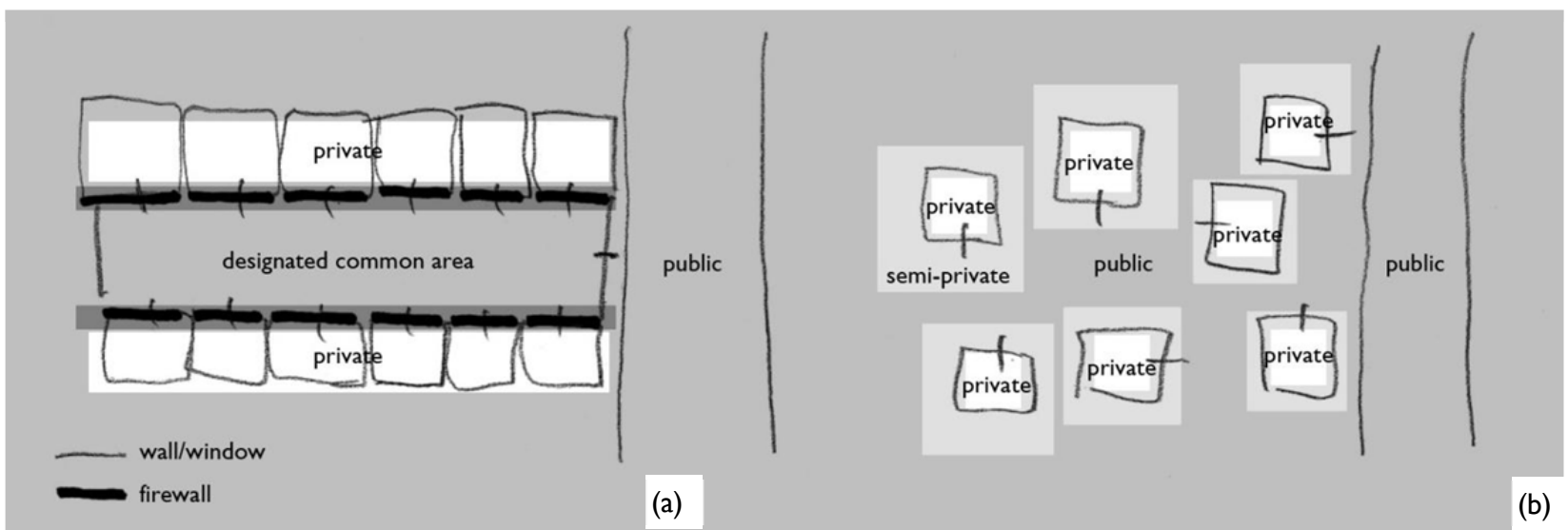

Figure 4. (a) Fireproof Wall in Designated Common Area; (b) Seamless Transition of Private and Public. (Source: Author, 2019)

\subsection{Residential Environment of Public-Private Interaction - Row-House} Japanese building regulation (Ministry of Land, Infrastructure, Transport and Tourism. Enforcement Regulations of Building Standards Act. Major building uses 08020, 08030, 08040.) categorizes apartment buildings into the following three groups: (I) 共同住宅 Kyodo-Jutaku (communal housing); (2) 寄宿舎Kishuku-Sha (dormitory) and (3) 長屋 Nagaya (row-house).

Communal housing is an apartment building with common use areas, such as corridors, halls and elevators. Dormitory is an apartment building with shared sanitary block (kitchen, bathroom, etc.). Row-house is an apartment building without common areas. It consists only of several private spaces.

In the living environment of the row-house, public space (pathways) is directly connected with private spaces. This is a low-level space without common areas (including elevators), a space where indoors and outdoors private spaces are densely packed. One could argue that this urbo-architectural type has the capacity for formation of living with significant level of public-private, indoor-outdoor interaction. This potential will be explored using examples from practice, applying the previously elaborated three spatial hypotheses based on the nature of predominant urban character of Tokyo: low-rise high-density (row-house residential environment); climate responsive semi-exterior space; and public-private interaction (abolishment of designated common area). 


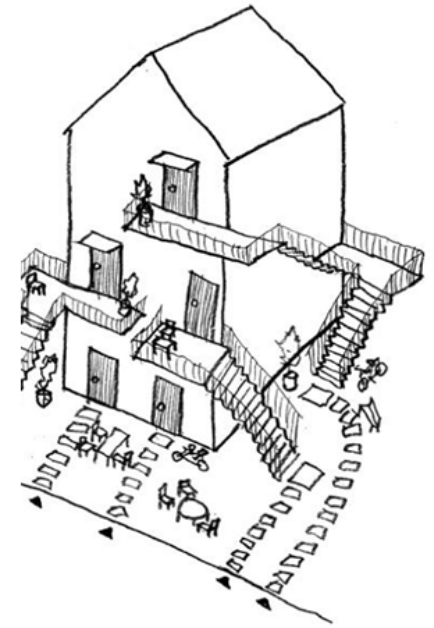

(a)

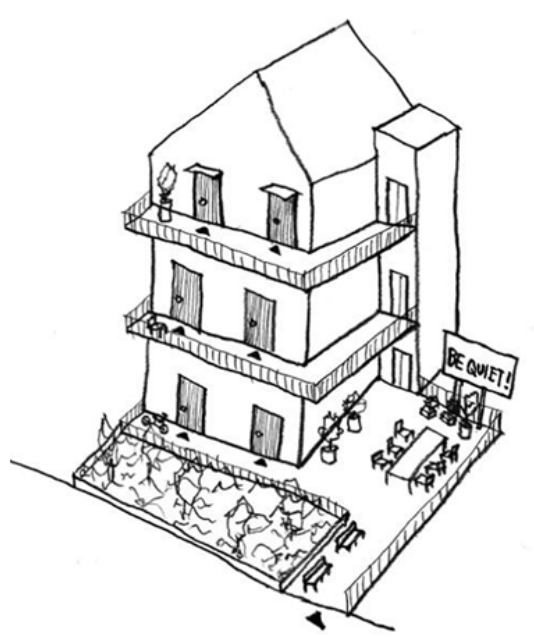

(b)

Fugure 5. (a) Row-house/Apartments without common use area;

(b) Communal Housing/Dormitory/Apartments with common use area

(Source: Author, 2019)

\section{Learning from Practice}

The first case is a row-house residential environment designed by the author of this study. In order to respond to the Japanese architectural particularities, definition of public space used in this paper is conditional and culture specific. Alternatively, it can be viewed as defined as semi-private space, but this designation lacks the previously mentioned particularities of the Japanese cultural and morphological context. Public space here includes (I) common spaces in residential areas and (2) not only publicly owned spaces (in Japan, only roads or parks) but also to the accessible private land connected to them. Dragon Court Village (Figures 7, 8 and 9) is a two-storey apartment building (row-house) in residential district of Aichi prefecture, Japan.

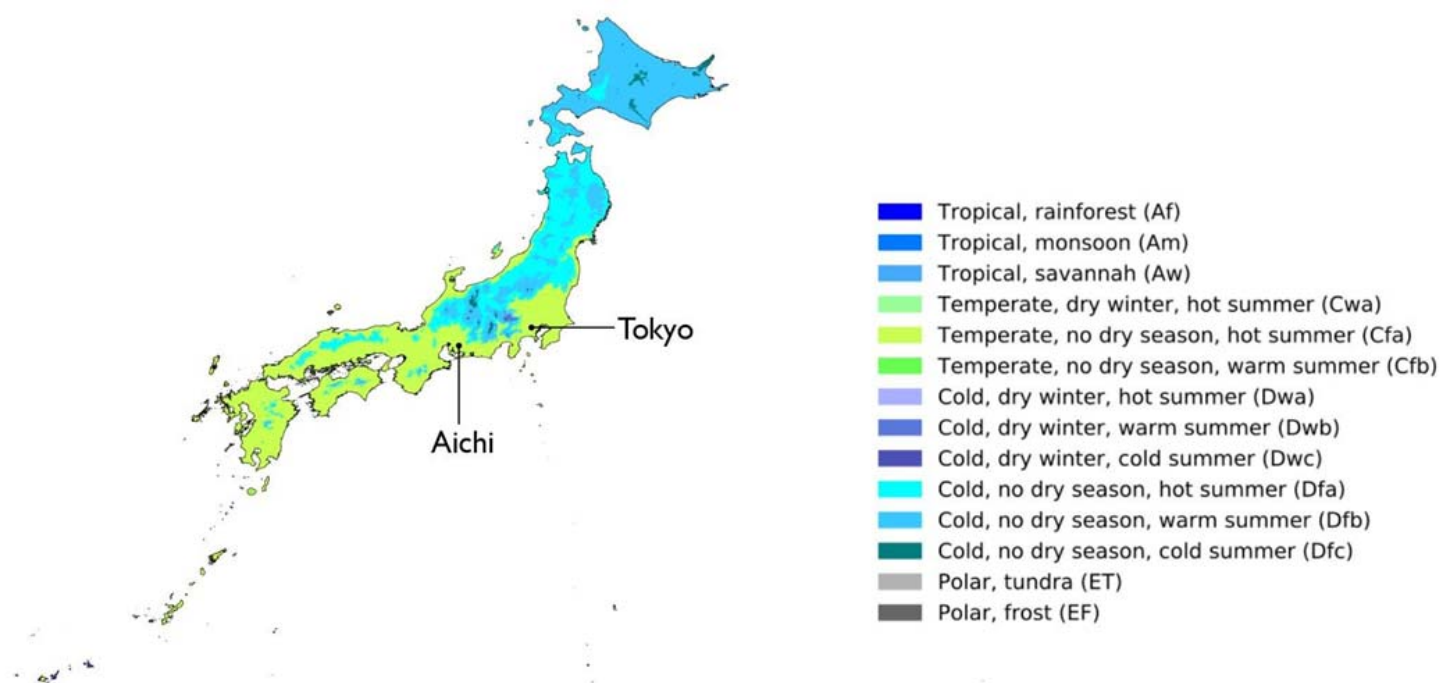

Figure 6. Present and future Köppen-Geiger climate classification maps at I-km resolution. Nature Scientific Data. (Beck et al., 2018'"; the location of Tokyo and Aichi, were added by the authors)

\footnotetext{
" Beck, H.E., Zimmermann, N. E., McVicar, T. R., Vergopolan, N., Berg, A., \& Wood, E. F. (20I8). "Present and future Köppen-Geiger climate classification maps at I-km resolution". Available at: https://commons.wikimedia.org/w/index.php?curid=74673722 [Accessed 8 Dec. 2019].
} 
The total floor area is 508 square meters, with a total of nine units. Its building was completed in 2013. Each dwelling unit can be accessed directly from the street, and there are no designated common areas such as common corridors or common halls. The main dwelling space is on the upper floor, and on the ground level there are small rooms/entrances and staircases only. Therefore, the ground level is mostly comprised of piloti spaces, open to the surroundings.
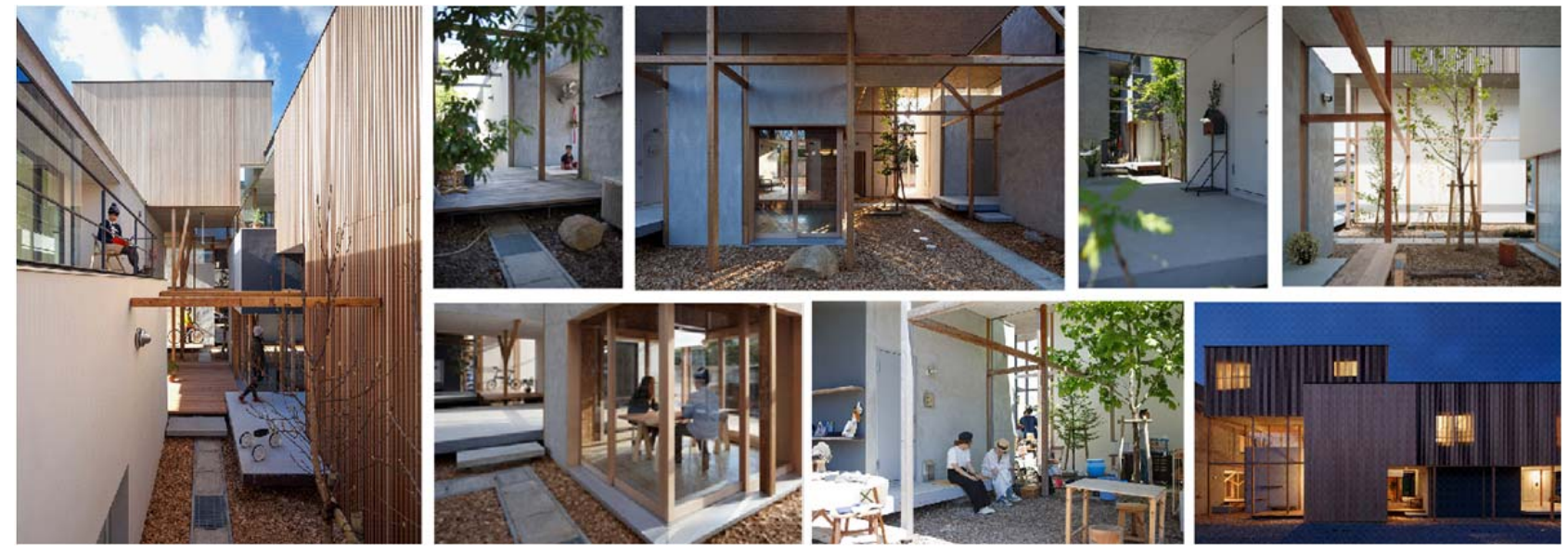

Figure 7. Dragon Court Village (Source: Hideki Ookura)

The characteristic found in this building is the dispersion of small rooms as annexes in the piloti space. In order to go to the annex from main dwelling space, residents go out from the entrance and walk through the piloti. The piloti space is a semi-exterior space where the upper massing casts a shadow and where the breeze flows. The airflow is designed and confirmed by CFD (computational fluid dynamics) analysis, guaranteeing bioclimatic comfort between the annexes.

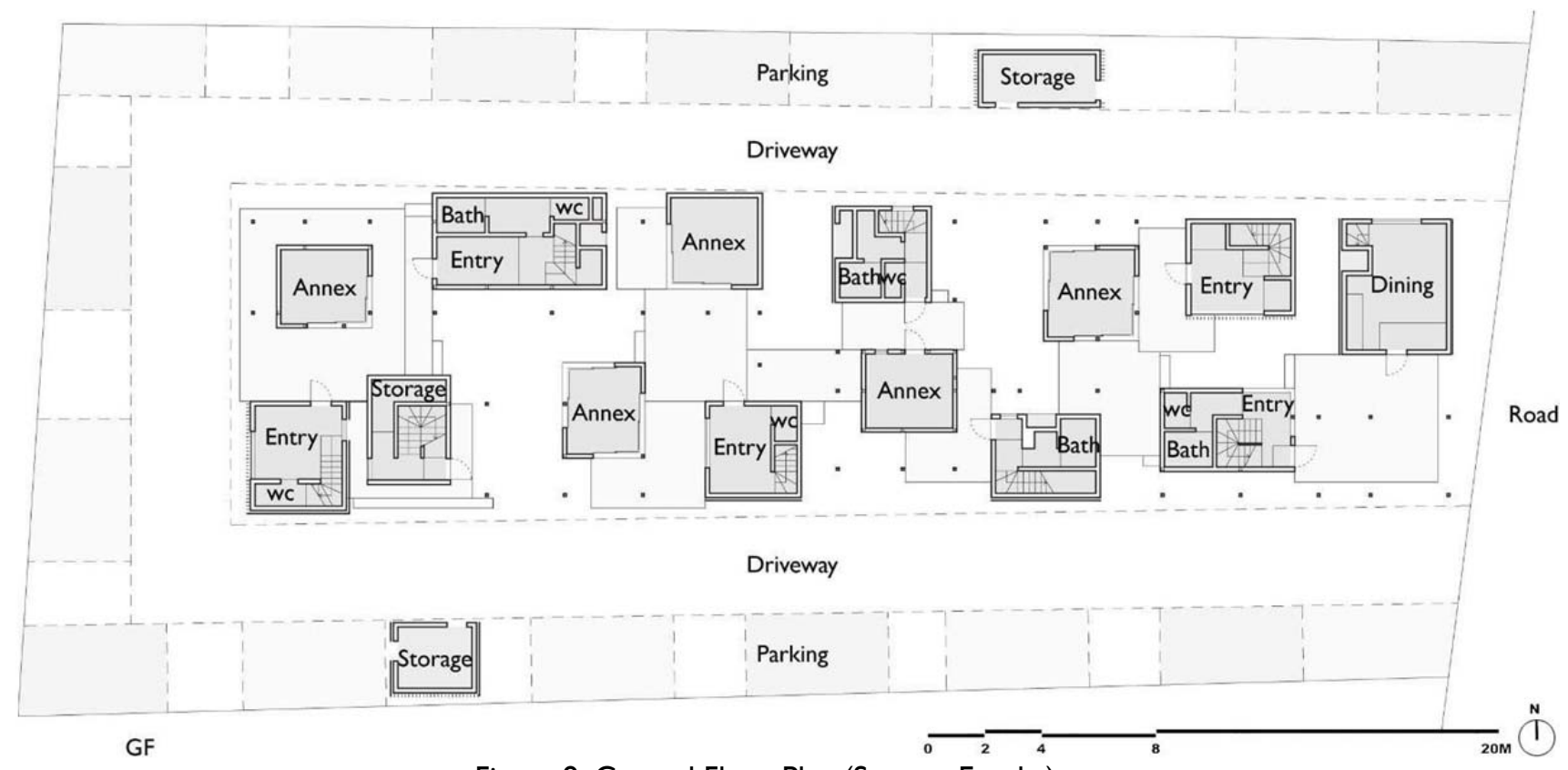

Figure 8. Ground Floor Plan (Source: Eureka) 


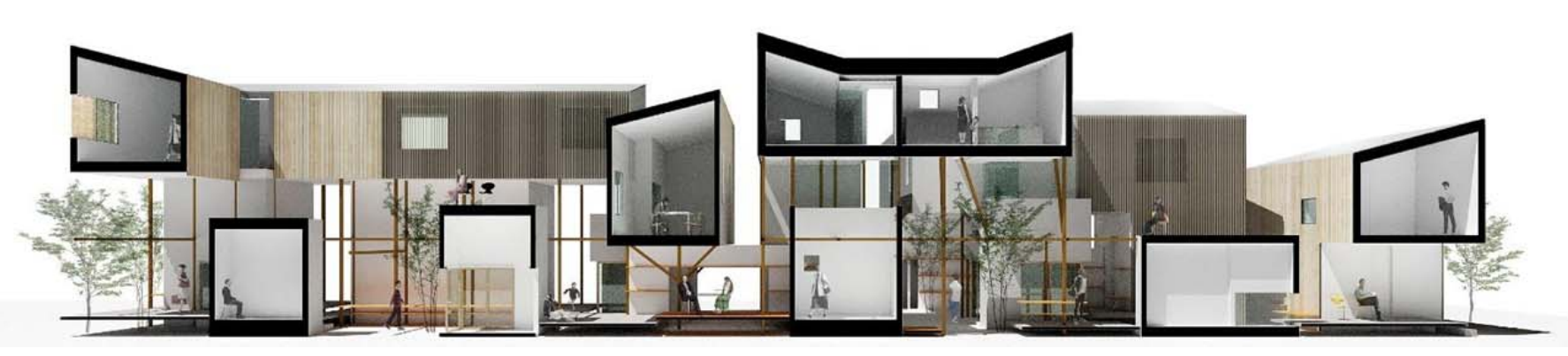

Figure 9. Rendered Longitudinal Section (Source: Eureka)

Not long after the building completion, residents have started transforming the piloti space into a lively place, in their own way. Each resident placed around their entrance a mailbox, umbrella stand, potted plant, bicycle, and so forth. The life of the residents had overflowed in front of each residential unit (Afuredashi), as it did in the old residential areas of Japan. Some of the residents have set up small flowerbeds.

The residents are mostly families - husband and wife (just one family has a child), a few residents are singles, and approximately half of the units were used as office space combined with dwelling. Most of the occupants were office workers (e.g. designer). Although the types of the residents are diverse, every resident started to enjoy life in their own way through Afuredashi-making. One of them, Ms. Y, started a small vegetable shop business in the annex on the ground level, while living on the upper floor. Because Ms. $Y$ utilizes her space as a vegetable shop, she is always present as a store manager in the piloti space. That makes space safe and inviting, and the number of outside visitors who come to buy vegetables increased. She gradually expanded her vegetable shop using more of the piloti space. But then, some changes occurred. Other residents also started actively utilizing their annexes and some of them made small interventions (e.g. adding a mezzanine floor for more storage, putting sheetrock on the wall for the display of goods). Such actions made the number of visitors increase further.

A year after the building completion, Ms. $Y$ began to run a weekend flea market. Mainly customers gathered, making friends among other self-employed members of the community. Additionally, coffee shops, snacks, clothes shops, and other shops opened, creating a modest, festival-like atmosphere. In the piloti space, divided by the entrance and the annex, small shops opened. The vacant space became a rest space and a playground for children. As all these activities were temporary in character, there was no conflict to be observed, neither was any reprimand issued by the property manager. Other resident joined in the flea market initiated by Ms. $Y$ and her friends, expanding the visitor number to include acquaintances and friends. The ground level (exterior/semi-exterior space) of the apartment building, gradually began obtaining a public quality, meaning anyone could visit and participate in the events. 

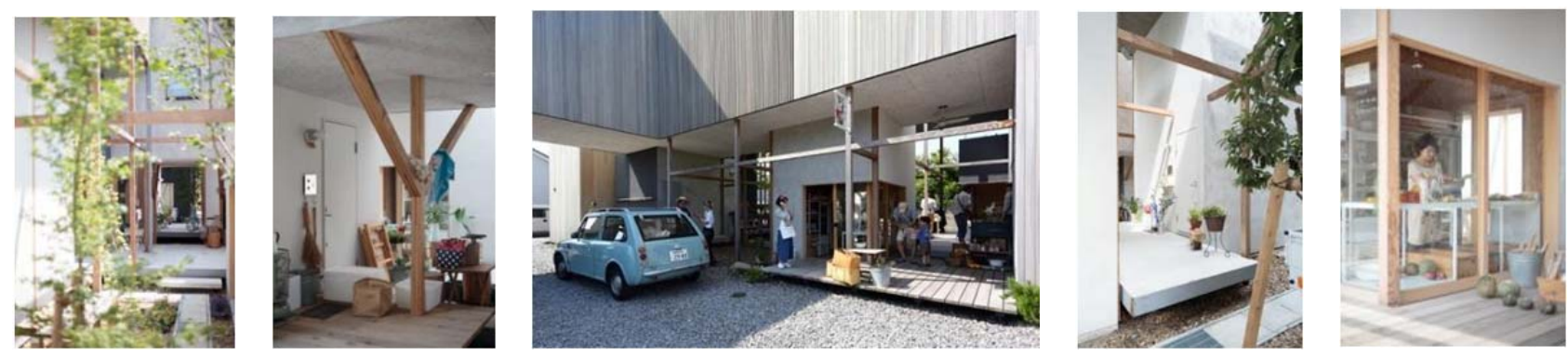

Figure 10. Afredashi in Dragon Court Village, 2014 (Source: Hideki Ookura)
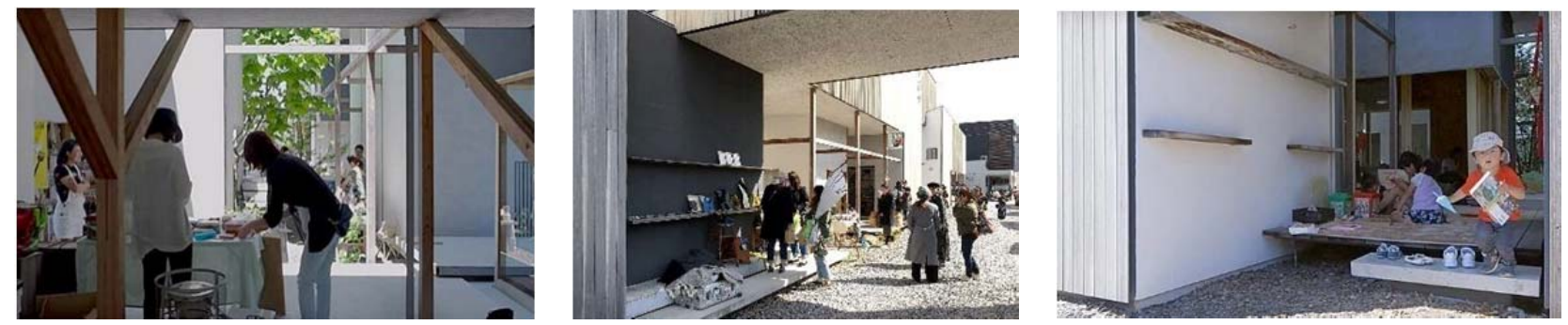

Figure II. Weekend Flea Market in Dragon Court Village, 2017 (Source: Hideki Ookura)

\section{I. Low-rise High-density}

As many residents used the annex on the ground floor, connected with the room on the upper floor (office, store, etc.), these spaces understandably developed a strong interdependence. Even though the annex is spatially modest, it is possible to confirm the merit of its smallness. Also, as previously noted, during the flea market, each store opens in every individual part of piloti divided by the entrance and the annex, and the vacant space became a rest space and the children's playground. This produced favourable results due to the high-density space configuration, creating numbers of small and convenient and easy-to-use spaces inside and outside.

\subsection{Climate responsive semi-exterior space}

The piloti area is designed as a semi-outdoor space where strong sunlight is blocked, and the wind passes through. Climate-responsively designed spaces in warm and humid climate encourage people to stay outside and to interact. The tendency of people staying in the semi-outdoor space was particularly remarkable at the time of the flea market, but people also stayed during times when there were no special events. Since almost all the Afuredashi, except signboards, were installed in the semi-outdoor space, this space was also effective in making the external space rather private-like.

\subsection{Public-Private interaction}

Because the piloti spaces were not originally designed for a specific purpose, the residents needed to consider its utilization purposes. According to the research on the alleys of Tokyo (Tsukishima, Chuo-ku, Tokyo) by Aoki \& Yuasa (1993, pp. 53), "Spaces that are open to the exterior are more likely to be used privately, by putting Afuredashi, rather than spaces that are closed". Aoki \& Yuasa (1993) state this tendency occurs not because "an area for private use is generated because there is an enclosed area (there is an area that is easy to personalize)", but because "Since there is no area in the open space in advance, using 
it for private use will result in private domination, and as a result, private domination will be strengthened", Aoki \& Yuasa (1993, p. 52). In other words, "the residents are not passively receiving the given space environment, but are actively working against the environment", Aoki \& Yuasa (1993, p. 53). This statement has been interpreted as positive, because the residents proactively define their own living surrounding, a practice not common in Japan. The user actively discovers the possibilities of the space without defined functions, so utilization of the space becomes more active, as the usage is discovered (by the user) thereafter. In this sense, 'non-functional' space is easier to use, due to their lack of a designated function. In this way, each resident applied their own setup to their spaces, influencing the neighbours' mental wellbeing through increased social interaction. As a result, shared spaces were created, or the entire area became a common space. From this observation, it can be said that the private space and the common space are not divided, but their functionality is continuous or mixed, and the rules and manners of the space were decided and utilized by the residents themselves. This is completely different from the 'designated common area' described above. Normally, the unwritten rule of this designation, in architectural and planning practices, for the given architectural typology is an area that is mainly utilized as a buffer or a transitional zone. Active usage and continued evolving of activities are uncommon, but it was not considered disruptive by the residence manager. Therefore, its usage was activated without perception of activities being in opposition to the guidelines and being prohibited.

\subsection{Challenges of Spontaneous Usage of Semi-Outdoor Spaces}

The following figures (Figures I 2 and I 3 ) show the transition of private areas (completed in 2013) to the present (as of 2019) that has been formed in outdoor or semi-outdoor spaces by comparing the range in which Afuredashi appeared.

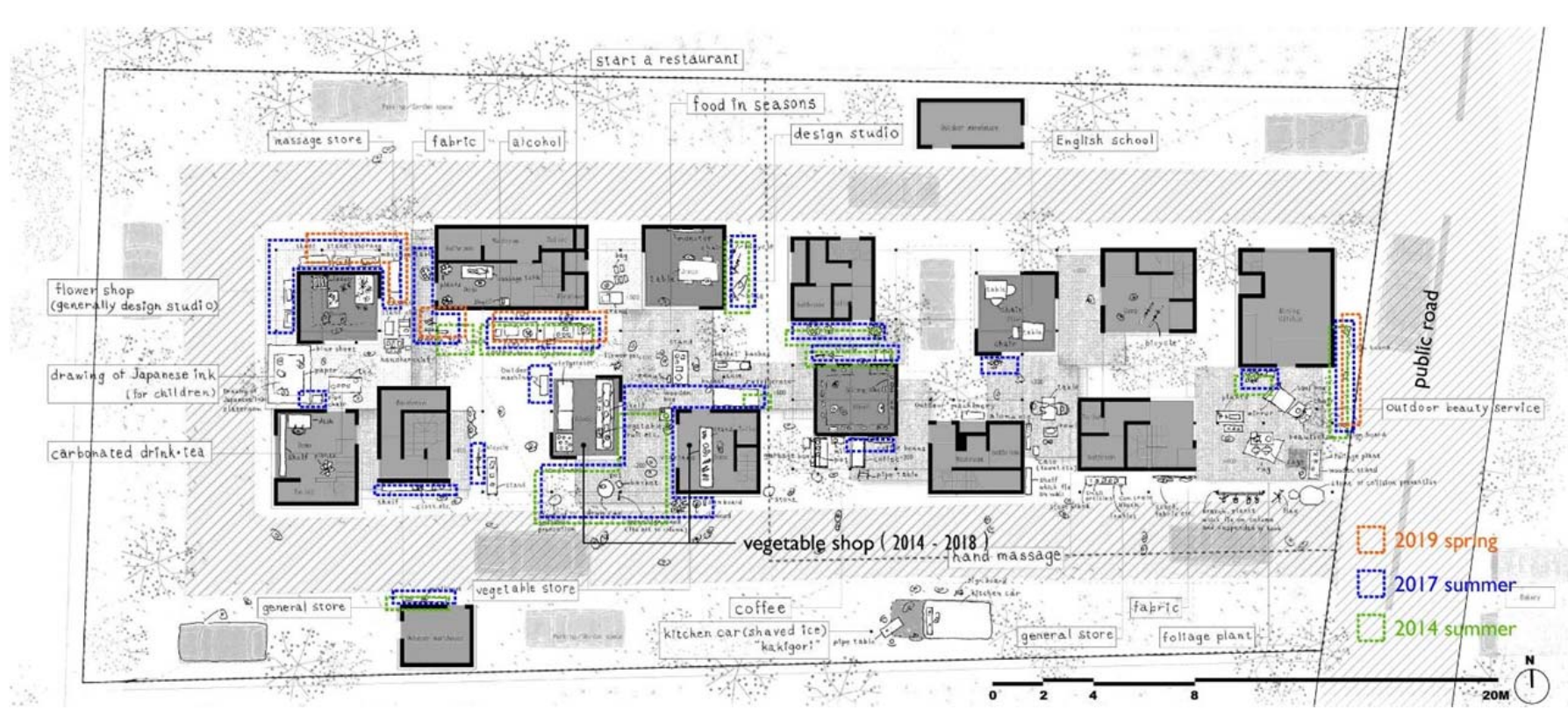

Figure 12. Transition of the Privately Used Area Afuredashi (2014, 2017, 2019) floor plan (Source: Author, 2019) 

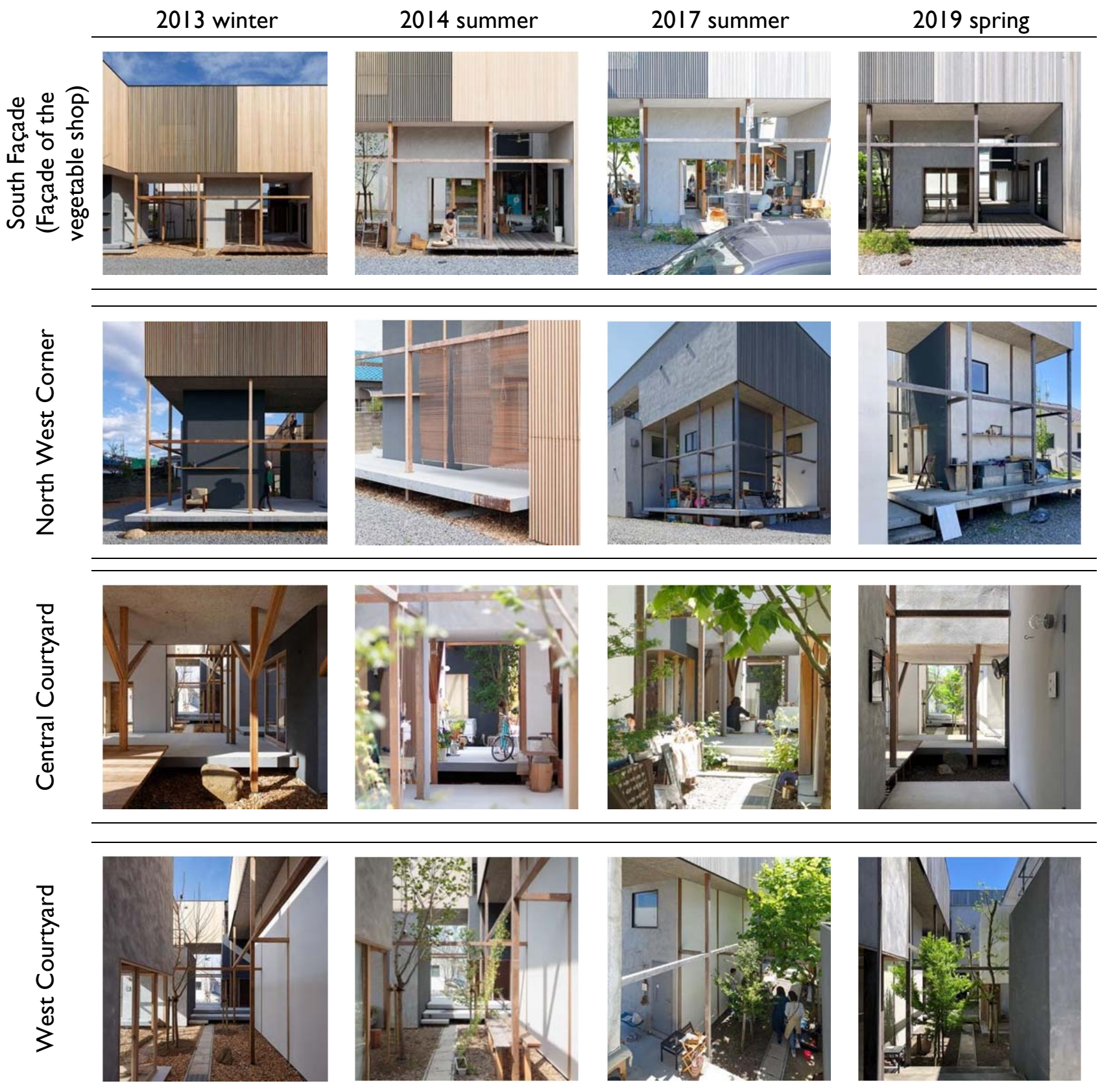

Figure 13. Changes in Spatial Operation of Private-Use Designated Areas (note the Afuredashi elements) (Source: Author (2019) and Hideki Ookura (2013-2017))

All semi-outdoor spaces were the location where the Afuredashi elements appeared. This is consistent with Aoki's (1993) Afuredashi observations. Also, many of the Afuredashi are on the west side of the site (opposite from the main road). It is also observed that more private areas were formed as far as possible from the main road. The same tendency is also noted in Aoki's study (1993), there are more Afuredashi near the centre of the alley (location farthest from the entrance) rather than the space near the entrance. However, the fact that several Afuredashi elements are located on the sites' west side has a lot to do with the location of the vegetable shop likewise located on the west side. Because the private territory had been increasing until 2017, as of 
2019 the existence of Afuredashi elements could only be partially confirmed. This is believed to have been caused by the relocation of Ms. $Y$ and the magnitude of her influence. Ms. Y relocated in 2018, and it is thought that this event is the major factor for the Afuredashi decrease in the 2019 spring. It is interesting that, although it was expected that the Afuredashi around her residence are removed, the amount of Afuredashi of the entire site have reduced too. So, a correlation between the residents' influence has been noted. The disappearance of the Afuredashi that used to exist signifies that the expansion of private usage onto the external space has not been established. It is ideal for private elements (e.g. Afuredashi) to spontaneously 'spill out' and eventually turn the (previously underused) space into a place fostering human interaction, but this did not happen. The hypothesis of this research, an opposite to the high-rise highdensity paradigm, theorized that the low-rise high-density spatial and morphological dispositions can generate public-private interaction and can also foster human interface, so it was partially confirmed. But the question that remains is 'how to verify this claim?'

\section{Case Study II: Minagawa Village}

Based on the examination in Section 3, a Tokyo case study which has a similarity to Dragon Court Village in terms of the architectural type, is selected to verify the feasibility and effectiveness in the contemporary situation. In the process of the selection of the case study, literature review of all the row-houses was carried out based on the Japanese architectural magazine Shinkenchiku ${ }^{12}$ for the period of 10 years (2009-2018).

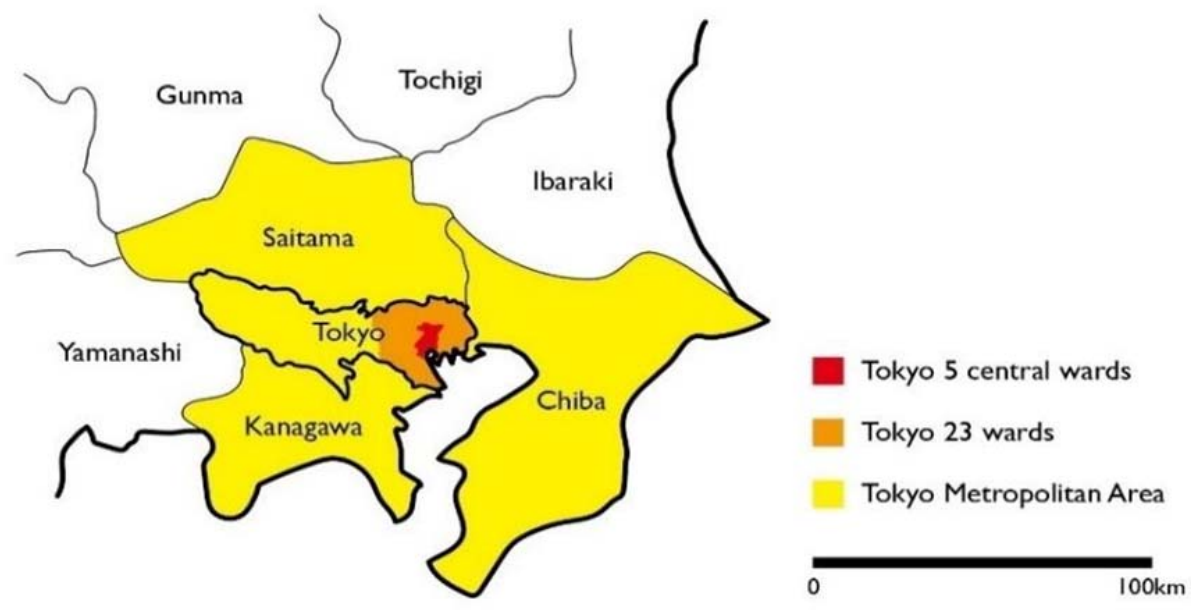

Figure 14. Tokyo Metropolitan Map (Source: Author)

There were 69 cases in Tokyo Metropolitan Area (Tokyo, Kanagawa, Saitama, and Chiba). Among those cases, 56 cases (81\%) were in Tokyo's 23 wards, and I 3 (19\%) were elsewhere. In more detail: 8 cases in Tokyo's 5 central wards, 48 cases in other Tokyo 18 wards, 5 cases in Tokyo (outside 23 wards), 8 cases in other Tokyo Metropolitan Area (Kanagawa, Saitama, and Chiba).

12 Shinkenchiku: Japanese architectural magazine that has the longest history in Japan, first published in 1925.

78 | The Journal of Public Space, 5(2), 2020 | ISSN 2206-9658

City Space Architecture / UN-Habitat 
Since there are no elevators in row-houses and all are low-rise (less than or equal to ground floor plus two storeys), the number of floors is not the subject of discussion. The focus is on 'semi-exterior' spaces. As previously mentioned, semi-exterior is the space adapting to the humid subtropical climate, blocking sunlight and allowing airflow. In addition, it is recognized as an important parameter which ensures the outdoor quality for staying, connecting private with public space. There were five cases with semi-exterior space with more than $20 \%$ of the total floor area. Most of the surveyed cases $(81 \%)$ were in the 23 wards of Tokyo. But the site areas in central Tokyo were comparatively smaller and in order to efficiently secure the maximum total floor area, they are box-shaped, with no room for semi-exterior spaces. Even if there is a semioutdoor space, it is not a space under the eaves, it is a space open to the elements. There were many cases with a courtyard, but there were few 'semi-exterior spaces' with a roof or overhead mass. This indicates that in urban areas priority is given to minimizing the construction costs (rising due to the reconstruction after the 201 I Great East Japan Earthquake and construction demand for the 2020 Tokyo Olympics ${ }^{13}$ ). Thus, a simple box-shape is applied as a design strategy. The tendency to go against climate responsive spaces in low-rise and high-density is observed as well as the trend of high-rise, high-density development. 'Boxing-up' is one of them. Of the five cases with semi-exterior space of $20 \%$ or more of the total floor area, there were two cases in the five central wards of central Tokyo. Two cases are Minagawa Village in Shibuya, Tokyo and Yoyogi Terrace in Shibuya. Minagawa Village applies rental row-house system. On the other hand, Yoyogi terrace is also row-house managed by division of ownership. Regarding the ownership pattern, like Dragon Court Village, Minagawa Village is chosen as a case study.
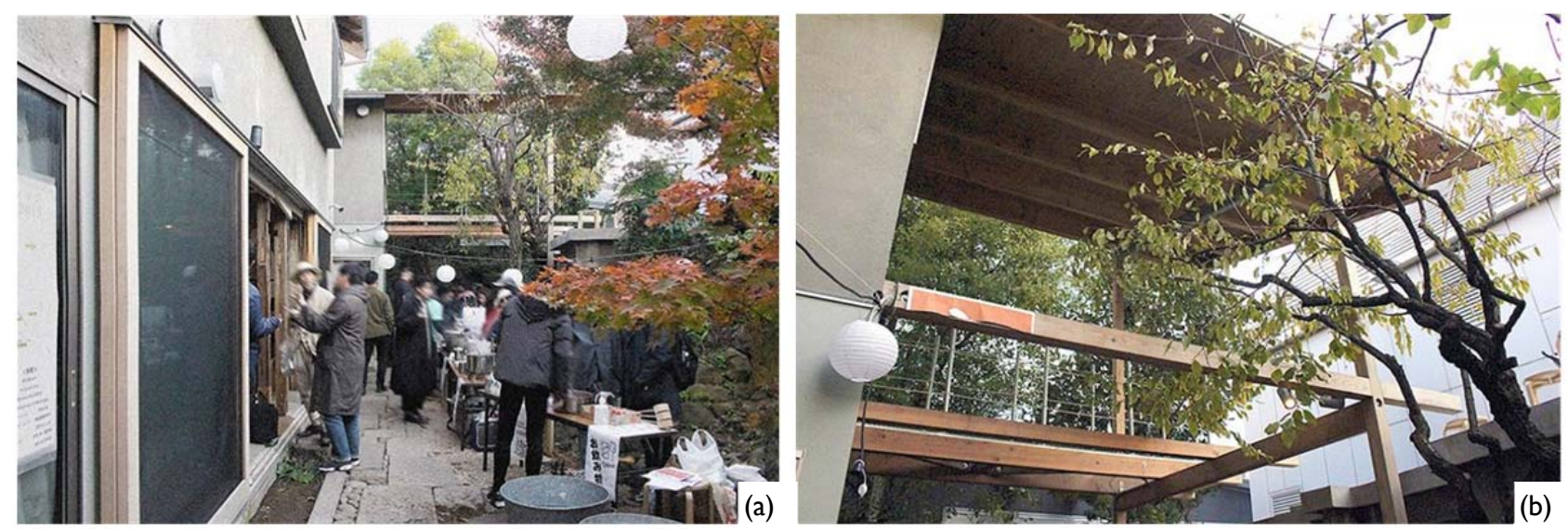

Figure I5. (a) Free Space (on the left) and garden (centre); (b) Roof Covered Semi-Exterior Space (Source: Author)

Primarily, the background on the design process and the architectural brief of Minagawa Village will be presented. Minagawa Village is located in Omotesando (jingumae, Shibuya-ku, Tokyo). The wooden house built in 1957 was repurposed as an apartment building, completed in 2018 and designed by Toyoaki Kamimoto, a founder of

${ }^{13}$ Construction Material Price Index. Available at: https://www.zai-keicho.or.jp/price_relative/ [Accessed 08 Mar. 2020] 
Saiseikenchiku Laboratory. The site area is 454 square meters, the building area is 238 square meters, and the total floor area is $42 \mathrm{I}$ square meters. It is a six-unit building complex, consisting of a four-unit row-house (residence combined with office), a café, and a retail shop. Four residential units and a café are connected via 'Free Space' facing the garden. Since Minagawa Village is row-house, this type of free space is not the common entrance/designated common area. The four residential units and the café have independent entrances; detailed explanation to follow.

According to Kamimoto interview notes (8 April, 2019), the architect himself ${ }^{14}$ was involved in the renovation works. The owner held a competition in which proposals were sought from multiple professionals in order to decide on the consulting company for this property. While the others proposed rebuilding, only the Kamimoto team proposed renovating and won the competition.
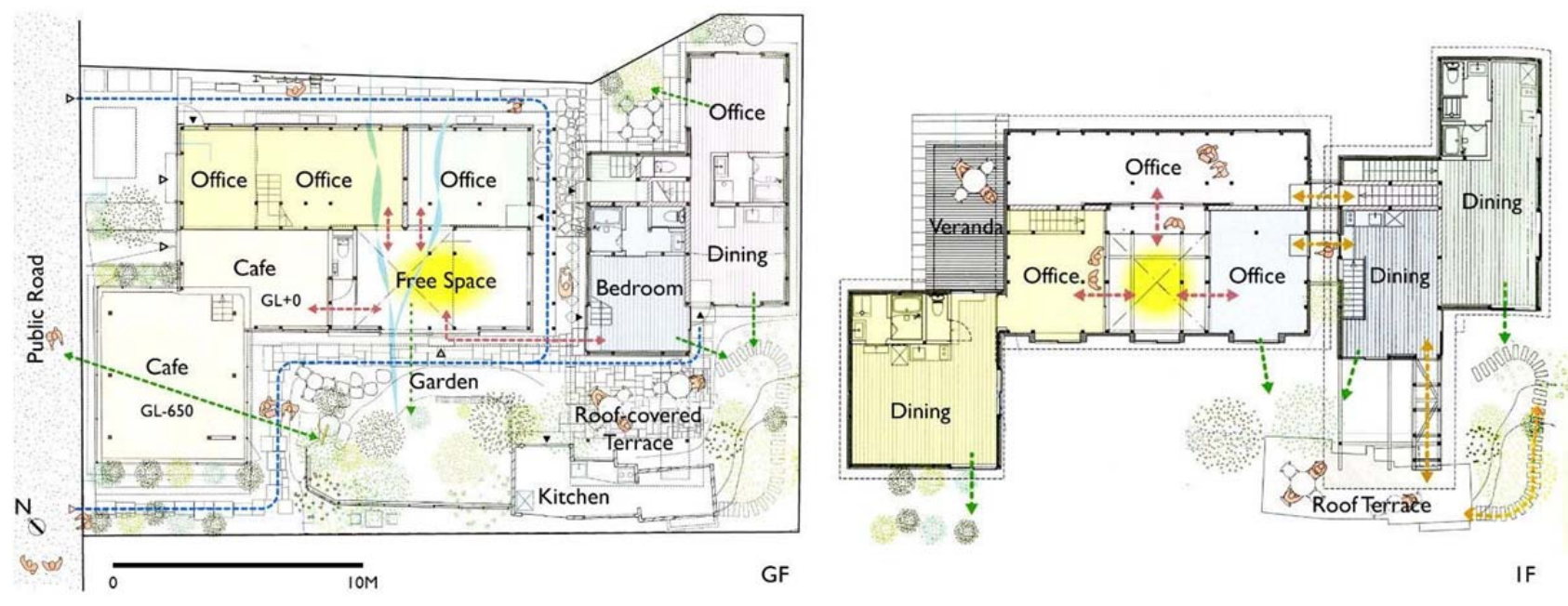

Figure 16. Minagawa Village Floor Plans (Source: Saiseikenchiku Laboratory)

The wooden house built in 1957 had been used as an apartment complex with repeated extension and reconstruction works. Some of the works were illegal because of the lack of building permission and completion inspection; it was understandable that other teams suggested the existing building be demolished and rebuilt. The existing building was not only illegal, but also did not satisfy the building regulations for this site and was not economically feasible. However, by legalizing the existing building, Kamimoto, as explained in the interview, proposed an "architecture and its mechanism to create a new community that cannot be achieved by a new building"6, and the proposal was accepted by the owner. Kamimoto' offices relocated to Minagawa Village for ten years after

\footnotetext{
${ }^{14}$ The semi-structured interview with Kamimoto was carried out on the $8^{\text {th }}$ April 2019 at the Free space in Minagawa Village-Style. Participants were Mr. Toyoaki Kamimoto (Principal architect at Saiseikenchiku Laboratory); Ms. Milica Muminović (Assistant Professor, University of Canberra. Her research extends the professional experience through studies conducted in Japan about identity, places, spaces in between architecture and urban design, public and private, with an emphasis on residential architecture in Tokyo); Ms. Ryoko Iwase (Principal architect / Landscape designer at Ryokoiwase. She works as an architect designing architecture, landscape design with public space in Japan; Satoshi Sano (Author and Principal architect at Eureka)
} 
completion, and he recruited the tenants and managed the shared spaces. Kamimoto is also currently involved in managing the entirety of Minagawa Village.
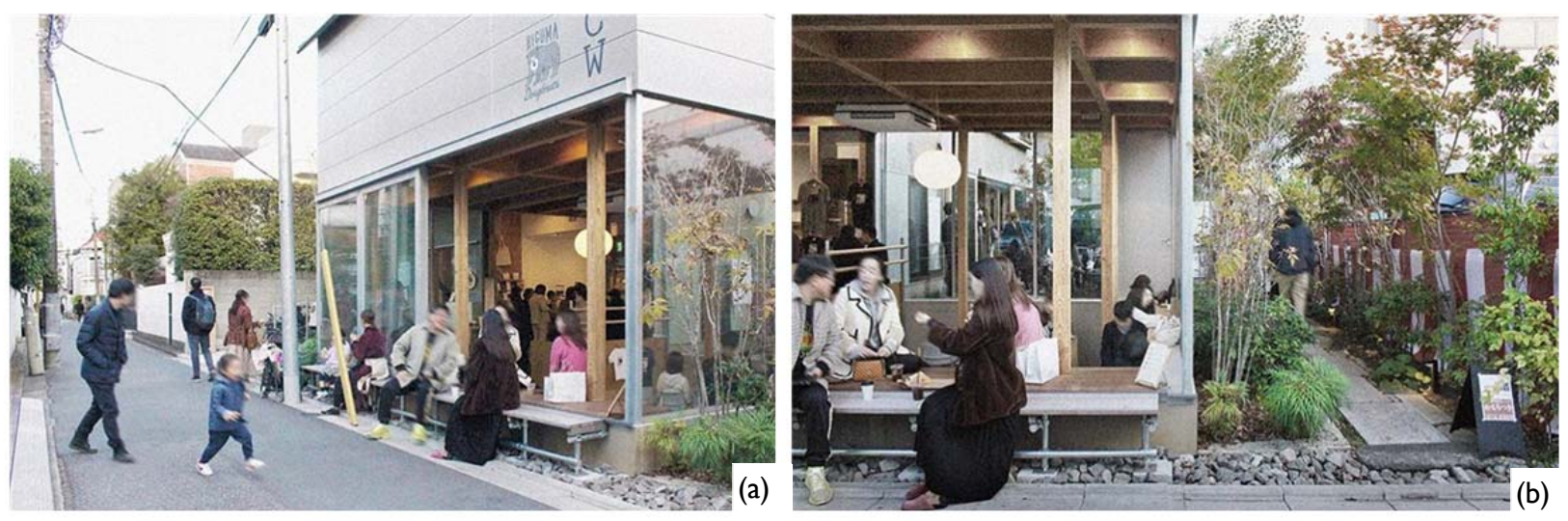

Figure 17. (a) Frontal Street of Minagawa Village; (b) View from the Street, Minagawa Village (Source: Author)
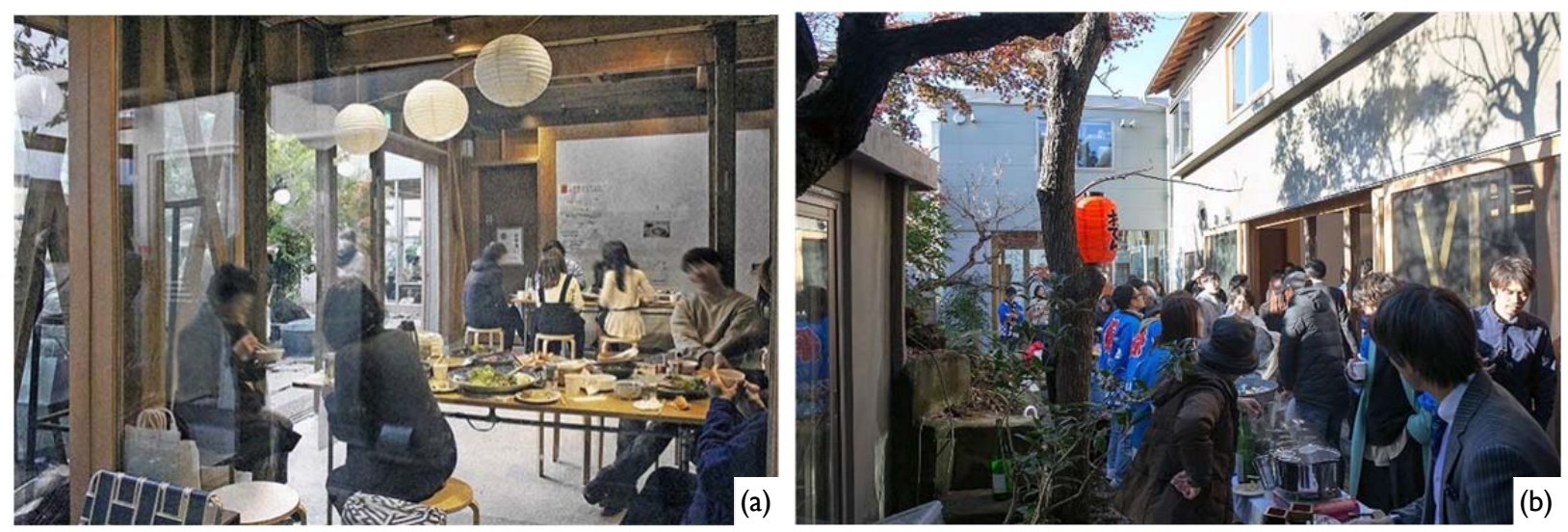

Figure 18. (a) Free Space, Minagawa Village (Source: Author); (b) Rice-cake Making Event in Minagawa Village (Source: Saiseikenchiku Laboratory ${ }^{15}$ )

\section{Discussion}

Considerations in regard to the public space inducing interactions in the case study will be discussed in the following section. This discussion is based on four points of views mentioned in Sections 2 and 3: low-rise high-density, climate responsive semi-exterior space, public-private interaction and operation of space.

\section{I. Low-rise High-density}

Similarly to the Dragon Court Village, Minagawa village has human-scaled, small and dense spaces assembling semi-exterior space and exterior space in a low-rise architecture with ground floor plus one or two storeys. The feature that the exterior space is divided to have spatial continuity is also similar in character. As Kamimoto noted in the interview "[...] space composition of row-house becomes (almost inevitably)

${ }^{15}$ Available at: http://minagawa-v.com/wp-content/uploads/20/8//2/IMG_3548@2x.jpg [Accessed 5 May. 2019]. 
elaborate and complex, but the spatial extensibility and redundancy that are generated by the complexity in space composition" (Kamimoto interview notes, 08 April, 2019). Minagawa Village is equally complex and highly dense. Since people have lunch in exterior/semiexterior spaces, "low-rise high-density space" particularities help to attract people to exterior/semi-exterior spaces.

\subsection{Climate responsive semi-exterior space}

Minagawa Village's 'Free Space' is a large 縁側Engawa-like space which can also be used as a semi-exterior space integrated with the garden. Engawa is the traditional spatial element of the Japanese architecture, which is the intermediate area between the interior and the exterior. Engawa is utilized as a space to go in and out, move between rooms, observe the exterior, to welcome visitors, etc. In other words, it is a "nonfunctional but versatile' space, which is also observed in the free space of Minagawa Village. When all the sliding doors are open, the space becomes a climate-responsive semi-exterior space, allowing airflow.

Tables and sofas are placed under the roof, forming a comfortable space in another semi-exterior space of Minagawa Village. The presence of these two semi-exterior spaces makes it easy to utilize the central garden (an exterior space without a roof or similar elements).

In addition, the temperature is lowered by the trees in the central garden and the airflow in the semi-exterior space makes it more comfortable, regarding temperature. The exterior and the semi-exterior spaces synergistically form a climate-responsive environment, providing people with opportunities for outdoor habitation and interaction.
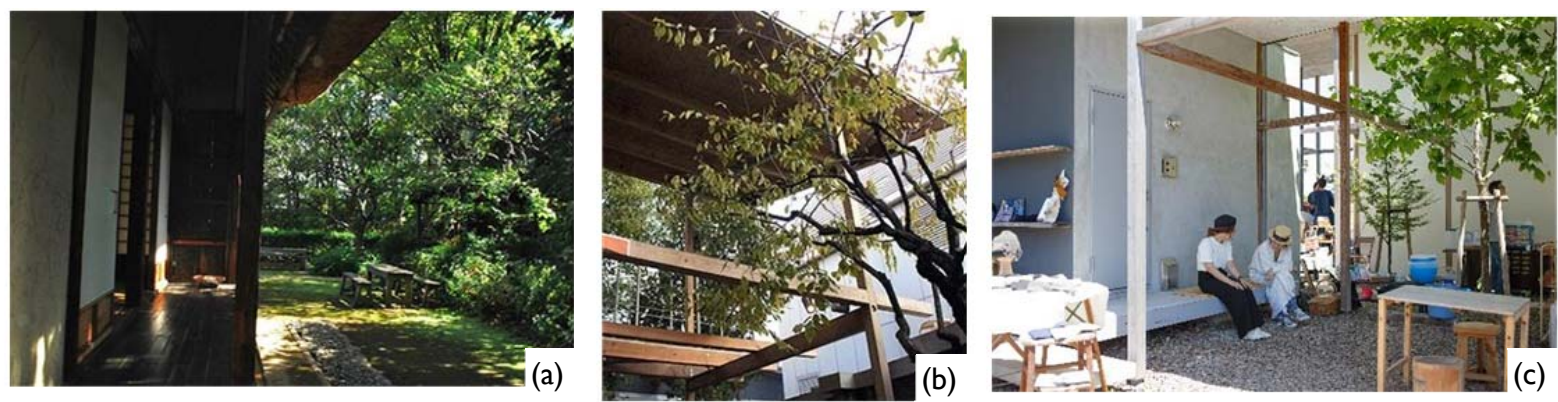

Figure 19. (a) Engawa Traditional Roof-covered Exterior Space (Source: karitsu ${ }^{16}$ ); (b) Minagawa Village Roof-covered Space (Source: Author); (c) Dragon Court Village Piloti Space (Source: HidekiOokura)

\subsection{Public-Private interaction}

There is a big difference between Minagawa Village and Dragon Court Village regarding Public-Private interaction. Specifically, the presence of Afuredashi elements is the point of interest: such elements were observed in the Dragon Court Village, but not in Minagawa Village. As it is the case with Dragon Court Village, it takes a certain amount of time after its construction before the Afuredashi elements appear, so even in Minagawa Village, Afuredashi emergence will occur over time, and the private area might

\footnotetext{
${ }^{16}$ Available at: https://www.flickr.com/photos/karitsu/8075303228 [Accessed 8 Dec. 2019].
} 
be formed spontaneously. However, the two cases show a significant difference in spatiality, demonstrating that the difference greatly influences the formation of the private areas in the semi-exterior and outdoor space.

The following figure (Figure 20) is the field note quoted from the research of narrow alley in Tsukishima, Tokyo, by Aoki and Yuasa (1993). It concludes that from the comparison of the number of Afuredashi, the open exterior space 'Semi-Open type' that allows passing through (rather than the dead space with high closed-ness of 'SemiClosed type') has a tendency to be more likely to be used privately such as spill overs elements of Afuredashi.

The two results represent the major difference between Dragon Court Village and Minagawa Village. Dragon Court Village allows people to pass through the massing or the exterior perimeter, categorized as Semi-Open type. Alternatively, Minagawa Village is conceptualized as a Semi-Closed type. The tendency noted by Aoki and Yuasa (1993) was also applied to Dragon Court Village and Minagawa Village, and Afuredashi were observed at Dragon Court Village, but hardly observed at Minagawa Village. That is, in the Semi-Open type, a private area is likely to be formed spontaneously in the exterior space, whereas in the Semi-Closed type, its formation is relatively difficult.

Therefore, if human interaction is to be created through the formation of a private area opening to the exterior and utilized as public space, Semi-Open type space is better than other types, as pointed out by Aoki and Yuasa (1993). Yet, the construction of low-rise, high-density redevelopment in modern Tokyo is carried out only on small or irregular sites with a small distance between developments. In such cases, the space configuration of the Semi-Open type is difficult to achieve, and then Semi-Closed type is adopted in the current situation, in Tokyo.

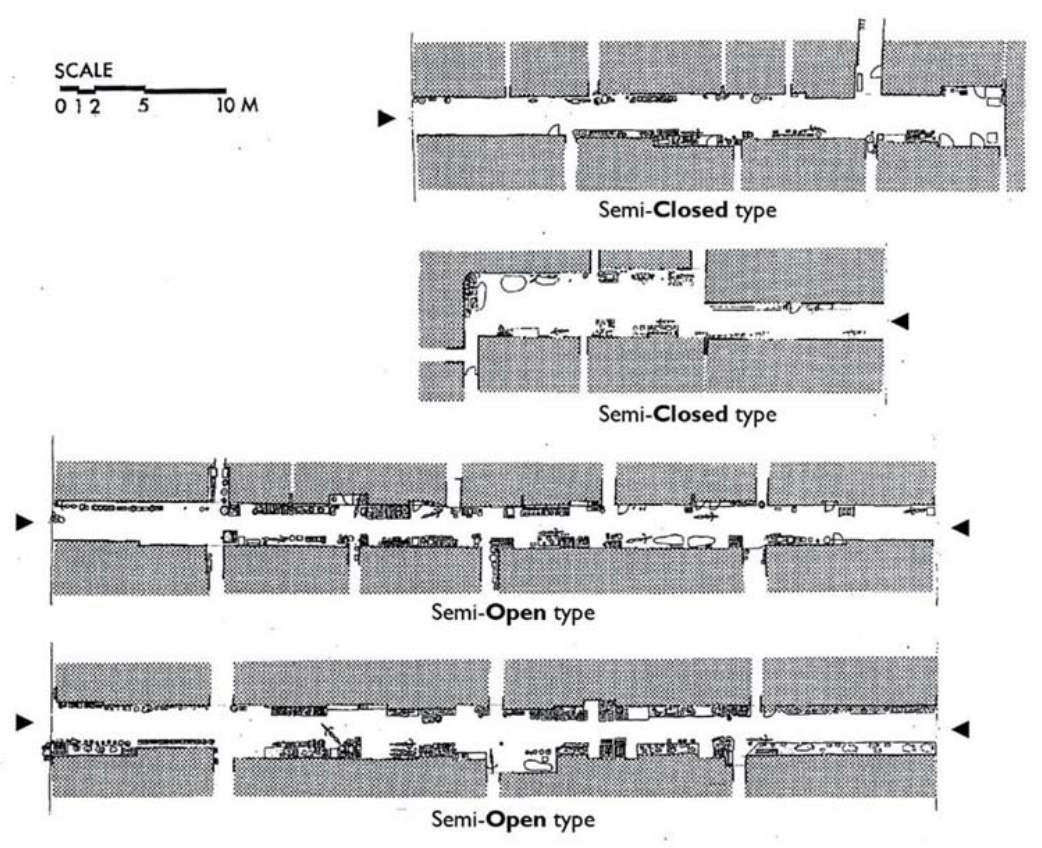

Figure 20. Field note of Afuredashi in Roji (Aoki, Y. \& Yuasa, Y., 1993)

Nevertheless, according to the interview with Kamimoto (Kamimoto interview notes, 08 April, 2019), although Minagawa Village, possessing Semi-Closed typology, does not 
have Afuredashi elements, so the public-private and human interaction are produced in this low-rise, high-dense environment with semi-exterior space thanks to his active management. It demonstrates that though the formation of a private area in exterior and public space is unlikely to occur spontaneously in Semi-Closed types, active operation makes it possible to facilitate public-private and human interaction. However, even in the Semi-Open type Dragon Court Village, Afuredashi (the formation of a private area outside) does not always exist, and the occurrence was triggered by a key user. Even in the Semi-Open type, the operation of space is desirable to induce collaboration.

In conclusion, low-rise, high-density, semi-exterior space has the potential to create public-private and human interaction, if certain conditions are met (e.g. designing semiprivate spaces that will facilitate interaction between residents and neighbours, innovative spatial management strategies, etc.). However, when dealing with small-scale, low-rise, high-density redevelopments in contemporary Tokyo, the space configuration tends to be a Semi-Closed type due to site constraints. Thus, not only the morphological conditions of low-rise, high-density and semi-exterior, but also the active operation are required to produce public-private, human interaction.

\subsection{Spatial Management}

The following section elaborates on the particularities of spatial operation. The relationship between the type of management and the ease of spatial sharing, discussed with Mr. Kamimoto (architect and manager of the property), is a very important argument. Certainly, there is relevance in discussing the spatial management, but on the other hand, the size, shape, and nature of the space are considered to have a great influence on fostering interaction, both spatial and social. It is the effect brought about by the spatial characteristics of low-rise and high-density, and public-private interaction that is achieved by the exclusion of designated common area.

"People cannot use the space unless they are actively involved" (Kamimoto interview notes, 08 April, 2019), is an understandable statement, but another person manages it, for both Minagawa Village and Dragon Court Village, even though the space is shared and used by residents. In Dragon Court Village, day-to-day managers and operators are the residents, including Ms. Y. However, to be precise, there is a manager who is the owner/landlord of the building and the property. The owner/landlord lives in the adjacent property. In Minagawa Village, Kamimoto clearly declares that he oversees the management because he is the assigned manager. (Kamimoto interview notes, 08 April, 2019) Other tenants might also have the habit of cleaning the area around the entrance. However, even if there is no 'self-management' and fully managed/operated by Kamimoto's office, tenants are familiar with Kamimoto and his employees and are familiar with spatial management. Thus, it would be possible for other residents to use the space, while communicating with the manager.

\subsection{Possible Future Urban Design Strategies}

The similarities found in Minagawa Village and Dragon Court Village can be thought of as occurring in large numbers for other architects, buildings and urban spaces as well. There is a limited number of architectural/urban spaces where a single architect can be involved. Even if an architect is involved in the design of small spaces of low-rise and high-density as much as possible, contribution to society through their involvement is 
negligible. However, if architects such as Kamimoto (Minagawa Village) and this study's author (Dragon Court Village) influence each other, it is sufficient and possible for the low-rise, high-density small spaces to be grouped together, gradually forming an urbanscale spatial environment. This is a bottom-up approach (architect-led) to urban design, contrasted by the top-down urban developments that involve clearing-out land and extensive redevelopment, destroying the cultural sustainability and human interaction.

\section{Conclusion}

This paper examined public spaces that create human interaction to reduce social isolation and achieve mental well-being in contemporary societies. It also demonstrated the effectiveness and the feasibility led by the approach to low-rise, high-density in terms of climatic and cultural characteristics in Tokyo, which was different from highrise, high-density urban development. The key approaches were low-rise, high-density, climate responsive semi-exterior space, public-private interaction, spatial management. The case study succeeded in creating human interaction, and although its effectiveness could be confirmed, there was a problem that it was temporary and was not sustained. As a verification of the feasibility of designing and building in Tokyo, in the urban area of Tokyo, there are not so many cases that adopt the approach of 'low-rise, high-density'. This is because area efficiency is maximized, and the construction cost is minimized. Although the feasibility of designing and building in Tokyo is not high at least as of 2019, there are cases where the approach of 'low-rise, high-density' has been realized like Minagawa Village, and certain effects for creating human interaction is confirmed. However, when using a small-scale, low-rise, high-density approach in contemporary Tokyo, the space configuration tends to be a Semi-Closed type due to site constraints. Thus, 'Low-rise High-density, Climate responsive semi-exterior space' requires the incentive reflected in various spatial strategies for the creation of public-private interaction and human interaction. Besides, regarding the Semi-Open type space where public-private interaction occurs spontaneously and Afuredashi is formed, operation of space is suggested for sustainable space utilization.

\section{References}

Ahlfeldt, G., Pietrostefani, E. (2019). The economic effects of density: A synthesis. Journal of Urban Economics. III, pp. 93-107. doi:10.1016/j.jue.2019.04.006.

Almusaed, A. (20I4). Biophilic and Bioclimatic Architecture: Analytical Therapy for the Next Generation of Passive Sustainable Architecture. Berlin: Springer

Aoki, M. (1985). A study on the change and development of housing style after the Meiji era. Jūtakukenchikukenkyūjohō, I2, Pp. I3-6I.

Aoki, Y. \& Yuasa, Y. (1993). Private Use and Territory in Alley-Space: Hypotheses and tests of planning concepts through the field surveys on alley-space Part I. Transactions of AlJ. Journal of architecture and planning. 449(0), Pp. 47-55.

Aoki, Y., Yuasa, Y. and Osaragi, T. (1994). Private Use and Territory in Alley-Space: Hypotheses and tests of planning concepts through the field surveys on alley-space Part 2. Transactions of AlJ. Journal of architecture and planning. 59(457), PP. I25-I 32.

Brumann, C. (20I5). Urban Spaces in Japan. Abingdon: Routledge. 
Clifford, S. (2018). Health Effects of Social Isolation and Loneliness. Available at: https://www.aginglifecarejournal.org/health-effects-of-social-isolation-and-loneliness/ [Accessed 5 May. 2019].

Diener E, Suh E, Oishi S. (1997). Recent findings on subjective well-being. Indian Journal of Clinical Psychology. 24, pP. 25-4I.

Exenberger, A., Strobl, P., Bischof, G., \& Mokhiber, J. (Eds.) (20I3). Globalization and the City: Two Connected Phenomena in Past and Present. Innsbruck University Press. Retrieved from http://books.openedition.org/iup//352.

Grondin, D. (1959). "Architecture and climate”, Moscow: Mir Publishers, pp. 79-86.

Japan Property Central KK. (20II). Building regulations in Japan. Japan Property Central.

Jinnai, H. (1995). “Tokyo: A Spatial Anthropology”. Berkeley: University of California Press.

Kamimoto, T. and Saiseikenchiku Laboratory. (2018). Minagawa Village. Shinkenchiku. 93(8), pp. 98- 107.

Kara, B. (20/9). The Impact Of Globalization On Cities. Journal of Contemporary Urban Affairs, 3(2), I08-I I 3. Retrieved from: https://doi.org// 0.25034/ijcua.20/8.4707.

Keene, D, tr. (1998). Essays in Idleness: The Tsurezuregusa of Kenkō. New York: Columbia University Press.

Khazaee, M., Darabi, S., Abdi, J. (2015). Globalization and its Ambivalent Effects on Cities. Journal of Applied Environmental and Biological Sciences. 5(9S), pp. 82I-829.

Kitayama, K., Tsukamoto, Y. \& Nishizawa, R. (20I0). TOKYO METABOLIZING. Tokyo: TOTO Publishing.

Kusanagi,H. (20I5) Regional characterization of US and Japanese climates from altitude reduction rate graph of temperature and temperature maps. Available at:https://www.metsoc.jp/tenki/pdf/2015/2015_06_0037.pdf [Accessed 5 May. 2019]. 
Mikami, H. and Suzuki, S. (1998). Movements and Issues on Openness and Closedness of Contemporary Japanese Housing. Housing Research Foundation annual report. 24, pp. 187196.

Maki, F. and Makabe, T. (Eds.) (2019). Another Utopia. NTT Publishing.

Ministry of Health, Labor and Welfare. (2008). Community making promotion meeting where elderly people can live in peace even if they are alone (Aiming at "isolated death" zero) report.Available at:https://www.mhlw.go.jp/houdou/2008/03/h0328-8.html [Accessed 5 May. 2019].

Ministry of Land, Infrastructure, Transport and Tourism. (20/9). Building Standards Act. Available at: $h$ ttps://elaws.egov.go.jp/search/elawsSearch/elaws search/lsg0500/detail?lawld=325AC000000020I.

Ministry of Land, Infrastructure, Transport and Tourism. (2019). Enforcement Regulations of Building Standards Act. Available at: https://elaws.egov.go.jp/search/elawsSearch/elaws_search/lsg0500/detail?lawld=325M50004000040.

Petermans, A. (2019). Subjective wellbeing and interior architecture: why and how the design of interior spaces can enable activities contributing to people's subjective wellbeing. Journal of Design Research. 17(I).

Radović, D., Boontharm, D. (Eds.) (2012). Small Tokyo. Tokyo: Flick Studio.

Rice, L. (2019). A health map for architecture: The determinants of health and wellbeing in buildings. In book Designing for Health \& Wellbeing: Home, City, Society. Publisher: Vernon.

Sasao, K. (2019). Public Hack. Tokyo: Gakugei Shuppansha.

Sorensen, A. (2004). The Making of Urban Japan: Cities and Planning from Edo to the Twenty First Century. Abingdon: Routledge.

Statistics Bureau of Japan. (2019). Statistical Handbook of Japan 2019. Statistical Handbook of Japan 2019. Retrieved February 15, 2020, from https://www.stat.go.jp/english/data/handbook/c01 I7.html. 
Suzuki, R. (20I4). Rethinking the floor area ratio easing legal system that creates Kokai-Kuchi. Tokyo Metropolitan University.

Tan, K.G., Woo, W.T., Tan, K.Y., Low, L., \& Aw, G.E.L. (20I2). Ranking the Liveability of the World's Major Cities: The Global Liveable Cities Index. Singapore; Hackensack, N.J: World Scientific Publishing Company. https://doi.org//0.1/42/8553.

Tardits, M. (2014). Tôkyô, Portraits \& Fictions. Tokyo: Kajima Publishing.

The National Association of Regional Councils (2012). Livability literature review: a synthesis of current practice. Washington. Retrieved from http://narc.org/wp-content/uploads/LivabilityReport-FINAL.pdf.

Tokyo Metropolitan Government. (2016). Land Use in Tokyo. Available at: http://www.toshiseibi.metro.tokyo.jp/seisaku/tochi_cltochi_5.html [Accessed 5 May. 2019].

Tokyo Metropolitan Government. (2019). Statistics of Tokyo.Available at: http://www.toukei.metro.tokyo.jp/ [Accessed 5 May. 2019].

Velasquez, O. M. (2009). Bioclimatic Architecture. Barcelona: Monsa.

Veenhoven, R. (2006). The four qualities of life. Ordering concepts and measures of the good life. In M. McGillivray, \& M. Clarke (Eds.) Understanding Human Well-being (pp. 74-100). Tokyo-New York-Paris: United Nations University Press.

Veenhoven R. (2008). Sociological theories of subjective well-being. In: M Eid, RJ Larsen (eds). The science of subjective well-being. New York: Guilford Press; 2008:44-6I.

Watanabe, K. (1989). Psychological Problems in High-rise Housing. Noise Control, I3(I), Pp. 4-8. World Health Organization. (2020). Japan. Countries. https://www.who.int/countries/jpn/en/. 